Sava Čavoški ${ }^{1}$, Aleksandar Marković ${ }^{2}$

${ }^{1}$ MDS informatički inženjering

${ }^{2}$ University of Belgrade, Faculty of Organisational Sciences, Serbia

\title{
Analysis of Customer Behaviour and Online Retailers Strategies Using the Agent-Based Simulation
}

\author{
UDC: 005.346:004.738.1 \\ 004.738.5:339 \\ DOI: 10.7595/management.fon.2015.0031
}

\begin{abstract}
This paper discusses the application of ABMS - agent-based modelling and simulation in the analysis of customer behaviour on B2C e-commerce websites as well as in the analysis of various business decisions upon the effects of on-line sales. By linking the areas of modelling based on agents and electronic commerce, this paper addresses the new opportunities for a quality assessment of consumer behaviour and reasons explaining this behaviour in e-commerce. The interactions of agents that make up this model are sublimated in the utility function that provides the basis for decision-making in the model. The rules of behaviour and interactions, included in the model through the utility function, denote the complexity of the decision-making process which occurs in evaluation and purchase of products in the part of B2C e-commerce. The simulation model implemented in the software NetLogo enables the monitoring of all interactions between the consumers (ConsumerAgents), seller-Internet sites (SellerAgents) and advertisement agents (BannerAgents) by generating the indicators of $\mathrm{B} 2 \mathrm{C}$ site business performance.
\end{abstract}

Keywords: ABMS, B2C, e-commerce, website, customer behavior, online retailers

\section{Introduction}

Electronic commerce has been expanding rapidly in the last decade or so and is now present in almost all industry branches and in a majority of developed countries' markets. In order that e-commerce business be successful, it is necessary that quality strategies of entrance on the market should be developed and implemented and that additional services should be offered that grant the customers better purchasing conditions, a possibility of service adapting and additional value for customers (Hyung, 2010) .

The approach used in this paper is to consider the possibility of applying agent-based simulation models as a basis in B2C business models evaluation for the purpose of improving the existing e-commerce strategies and obtain data that can be used in business decision analysis. Modelling and simulation based on autonomous agents and interactions among them are some of the more recent approaches in complex system simulation modelling (Miller and Page, 2007; Prokopenko et al., 2009). In the applications of models based on agents in the social processes people are modelled as agents, while their social interactions and social processes are modelled as interactions among these agents (Gilbert and Troitzsch, 2005).

\section{Consumer behaviour model}

The study of the consumer population, their habits and behaviour serves as basis for the B2C electronic commerce analysis. This analysis is of vital importance for B2C shareholders and managers, marketers, sales people, but also for the consumers themselves. The consumer analysis is meant to analyse the consumers' needs - what, why and how they purchase. Consumer behaviour can be described as a set of activities prospective customers undertake in searching, selecting, valuing, assessing, supplying and using of prod- 
ucts and services in order to satisfy their needs and desires. These also include decision-making processes that both precede and follow the above-mentioned activities (Belch 1998; Schiffman et al., 2009; Solomon, et. al 2009). In making their decisions to purchase a product, online shopping consumers go through different phases. The phases are similar to those present in traditional shopping, however, the manner in which they are carried out differs. Generally speaking, in their decision-making process, consumers go through the following stages (Engel J et.al, 1994): problem awareness, information search, evaluation of alternatives, decision on purchase and post-purchase evaluation.

The following text will further describe the impact factors in purchasing decision-making and the links among individual consumer characteristics, website characteristics, the online seller business strategies and the purchasing decision-making process. According to Changa et al., 2005, the factors that affect the consumer's decision can be classified as follows:

1. Perception of characteristics of the Internet as a sales channel

2. Characteristics of the Internet site or product

3. Consumer characteristics

The following Figure presents the key impact factors in the purchase decision-making process, with their most important attributes.

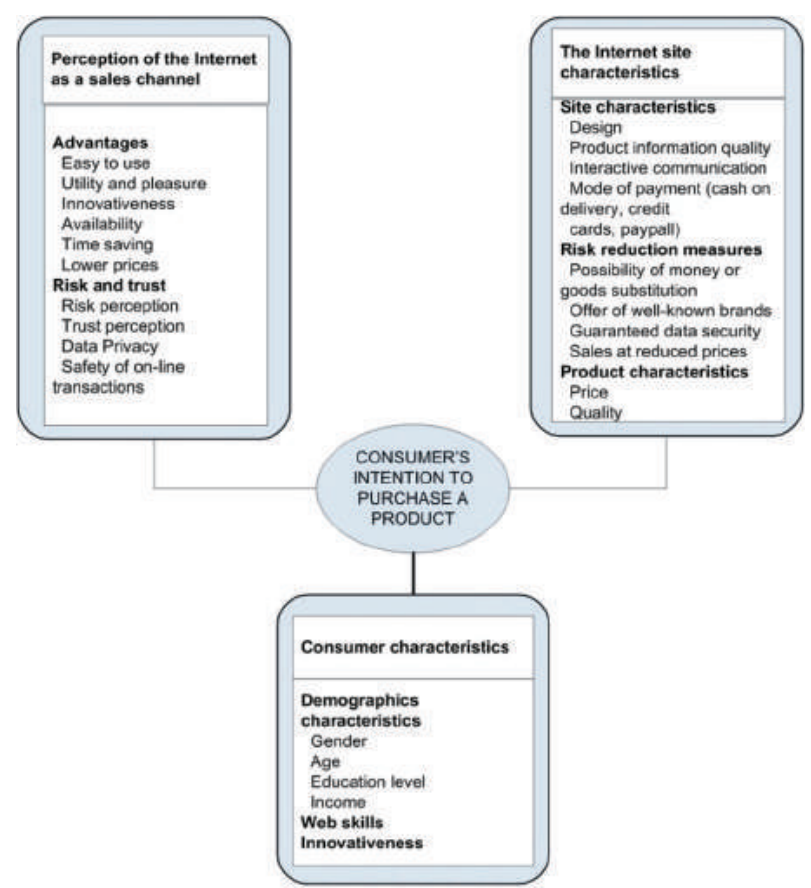

Figure 1. Factors of impact upon consumer behaviour in online purchasing

Upon defining the factors affecting consumer behaviour in online purchasing, our next step in building the model is to link consumers, on the one hand, and the sellers (Internet sales sites), on the other, and to determine the manner in which they communicate. Hence in this model we observe consumers with their social and cultural characteristics, on the one hand, and the market, namely online shops and intermediaries in sales with their e-business and e-marketing strategies, on the other. The model also takes into account the impacts of the on-line community and social networks on forming consumer decisions in online purchasing, whose influence increases daily. The model treats the consumer's decision on purchasing as the outcome variable.

When building a model, attention was paid that it should be really applicable and also that it should include as many impact factors as possible. The model is by nature dynamic and models a complex purchasing process in an online environment. It is characterised by a flexible structure that can be adjusted to individual needs and to specific phenomena. 


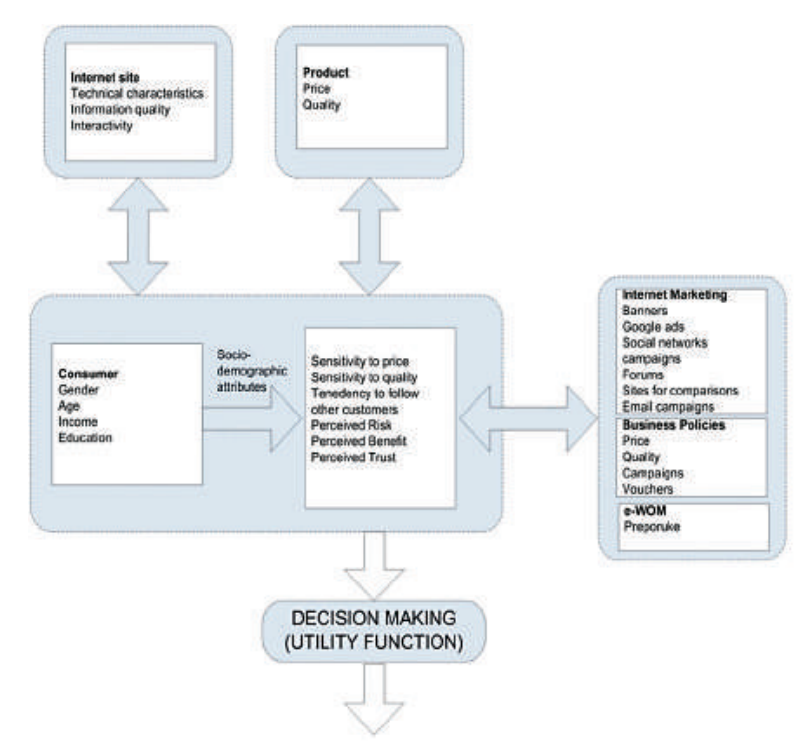

Figure 2. Consumer decision-making model in $\mathrm{B} 2 \mathrm{C}$ electronic commerce

The model shown in Figure 2 focuses on three segments: the seller segment, the consumer segment and the communication channel segment. The seller is the Internet site dealing in B2C sales of products and/or services. The most important site characteristics contained in the model are the technical characteristics: infrastructure, software support, website design and the quality of information on the products offered via the website. The consumer segment observes online consumers. The model monitors the impact factors concerning their attitudes, goals and beliefs (Figure 1). The communication channels are the online (Internet) and traditional channels of communication. The model under consideration is confined only to the effects of online communication channels application. In addition to the three described segments, the model includes business strategies created by the seller, whose aim is to increase sales and build consumer trust. The model allows for varying the input variables that simulate the effects of implementation of different business strategies, primarily those referring to price changes and product quality attributes. The model also helps track the effects of Internet marketing as a business strategy segment.

\section{Simulation model development}

In the previous section we identified the key entities of the model and elaborated on the fundamental theoretical concepts related to consumer behaviour, their attributes that play a key role in online purchase and the decision-making processes taken into consideration in defining the logical model of B2C online purchase system. In order to build an agent-based simulation model, it is necessary that key entities of the logical model should be presented as agents and their interactions be transformed into rules of behaviour. In this process, it is also necessary that a high level of compliance with a real system that is modelled should be ensured, which can be checked by the system validation and verification processes (Radenkovic et al., 2001).

In the observed simulation model, the prospective consumers go through all the stages of online purchase. They first find the B2C online shops of interest, then they search for information on the products, form their own opinion of the product and/or service (utility function) and finally make a decision to buy (regardless of whether these are consumers that buy only once or consumers that remain loyal after their first purchase). 


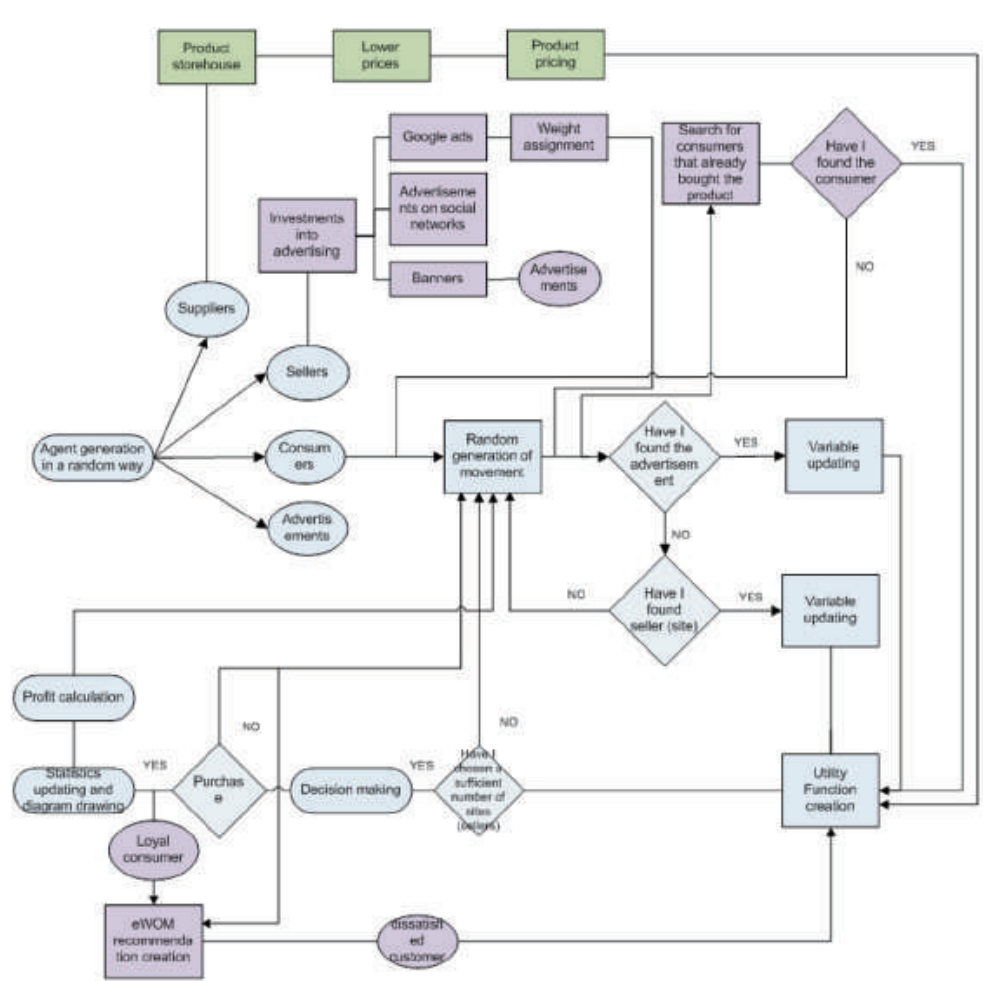

Figure 3. Graph of online purchase flow process in the simulation model

Figure 3 shows the basic steps in the simulation model, blue boxes represent the basic simulation flow. In the first step the simulation model forms a virtual market by generating agents: consumers (ConsumerAgents), sellers-Internet sites (SellerAgents), suppliers (SuppliersAgents) and advertisement agents (BannerAgents), on the basis of input variables.

The Consumer Agent models an individual consumer and his/her purchasing habits. The model can observe the behaviour of each individual consumer or a group of consumers. It is of key importance that we identify consumers with similar behaviours and needs and segment them for the purpose of targeted marketing campaigns (Klever, 2009). Agents that represent consumers in the model are generated by categories (on the basis of classification in (Moe 2003; Moe, Fader, 2002), and depending on their intention when visiting an online sales site:

1. Direct consumers: they visit the website with the intention to purchase a particular product; they rarely leave the website without having purchased.

2. Consumers who search/reason: they generally intend to buy a product from a certain category; it is possible that they make their purchase after several visits and comparisons with other websites and shops.

3. Hedonic browsers: initially, they do not intend to purchase a product; if made, a potential purchase is exclusively the result of stimuli from the site.

4. Information gathering visitors: visit website to gather information without any intention of buying.

The ConsumerAgents are assigned colours so that their behaviour in the model should be tracked separately. In generating ConsumerAgents, each agent is assigned characteristics shown in Table 1. 
Table 1: ConsumerAgents input parameters

\begin{tabular}{|l|l|l|l|}
\hline Label & Definition & Value & Distribution \\
\hline $\mathrm{G}_{\mathrm{i}}$ & i-th ConsumerAgent gender & input variable & Random 50\% \\
\hline $\mathrm{A}_{\mathrm{i}}$ & i-th ConsumerAgent age & input variable & $(18+$ random 60) \\
\hline $\mathrm{I}_{\mathrm{i}}$ & i-th ConsumerAgent income & input variable & $(5+$ random 10) \\
\hline $\mathrm{RS}_{\mathrm{i}}$ & $\begin{array}{l}\text { i-th ConsumerAgent sensitivity to } \\
\text { website rating }\end{array}$ & input variable & Random (0-1) \\
\hline $\mathrm{K}_{\mathrm{i}}$ & $\begin{array}{l}\text { i-th ConsumerAgent sensitivity } \\
\text { to product price }\end{array}$ & input variable & $\begin{array}{l}\text { Depends on } \mathrm{I}_{\mathrm{i}}-\text { wealthier } \\
\text { consumers are less } \\
\text { sensitive to price }\end{array}$ \\
\hline $\mathrm{W}_{i j}$ & $\begin{array}{l}\text { i-th ConsumerAgent sensitivity to a } \\
\text { particular product attribute }\end{array}$ & input variable & Random (0-1) \\
\hline$A D S_{i}$ & $\begin{array}{l}\text { i-th ConsumerAgent sensitivity to } \\
\text { advertisements }\end{array}$ & input variable & Random (0-1) \\
\hline $\mathrm{Ft}_{\mathrm{i}}$ & $\begin{array}{l}\text { i-th ConsumerAgent sensitivity to other } \\
\text { agents - consumers' decisions }\end{array}$ & input variable & Random (0-1) \\
\hline
\end{tabular}

The Internet sellers (B2C e-commerce websites) are modelled as SellerAgents. The model presumes that each sales website sells one brand, and the seller is assigned a particular colour for the purpose of identification and visual tracking in the model during the experiment. When generating at the beginning of the simulation, agents are randomly assigned attributes shown in Table 2.

Table 2: SellerAgents input parameters

\begin{tabular}{|l|l|l|l|}
\hline Label & Definition & Value & Distribution \\
\hline brand_seller & type of brand sold by SellerAgent & & Random \\
\hline $\begin{array}{l}\text { cbrand- } \\
\text { price }\end{array}$ & initial product price & input variable & Random(0-100) \\
\hline $\begin{array}{l}\text { sales- } \\
\text { volume }\end{array}$ & number of sales & output variable & \\
\hline $\mathrm{R}_{\mathrm{i}}$ & site rating & $\begin{array}{l}\text { site rating by } \\
\text { consumers } \\
+1=\text { positive, } \\
-1=\text { negative }\end{array}$ & \\
\hline Find $\mathrm{me}$ & initial search weight & input variable & Random(0-100) \\
\hline
\end{tabular}

In addition to consumers and sellers, the model includes SupplierAgents, which are also generated at the beginning of the simulation, under the assumption that they have an unlimited storage of products. One supplier is generated for every brand and is assigned the same colour as the respective SellerAgent.

The fourth type of agents are BannerAgents. They serve to model the effect of Internet advertisements (banners) on purchase decision-making. When they are generated, they are assigned the colour on the basis of which they are tracked in the simulation experiment.

Upon generating agents and forming a virtual market, ConsumerAgents start searching for and evaluating products. The search is carried out via agents' random surfing through virtual market where they interact with other ConsumerAgents, SellerAgents and BannerAgents. With the proposed model it is possible to observe the effects of different strategies of SellerAgents on the effects of Internet sales. By expanding the model, it is possible to observe the effects of business strategies related to Internet advertising (purple boxes in Figure 3 ) and/or related to product prices (green boxes on Figure 3).

Purple boxes in Figure 3 together with the basic model (blue boxes in Figure 4) show the model that takes into consideration different business strategies of Internet advertising. The development of social networks and Google services resulted in B2C e-commerce companies predominantly using these channels to market their products today. Customers with previous experience with online purchases display a tendency to share both positive and negative experiences about the purchase they made (eWOM effect) (Godes, Mayzlin, 2004). The model employs the following marketing tools: 
- eWOM (interaction with other agents).

- Search weight (weights on the basis of which agents search the websites);

- Advertisements with banners (BannerAgents);

During their surf through virtual market, ConsumerAgents "look for" BannerAgents in a certain radius surrounding them (input variable with the semantics of number of banners the ConsumerAgent sees during his search), thus simulating the impact of different marketing strategies upon consumers' attitudes when choosing a product on the Internet. Bearing in mind that not every consumer reacts to banners in the same manner, one input parameter of each ConsumerAgent is sensitivity to marketing campaigns. Thus the consumer's inner sensitivity (perception) to the offered product is modelled. Each ConsumerAgent "memorises" a number of reviewed BannerAgents, that is, brands they represent.

Surfing on, the ConsumerAgent randomly finds Internet websites (SellerAgents). Finding different sellers may be entirely random or affected by search weight on certain SellerAgents to which the ConsumerAgent reacts. The number of websites browsed in this manner makes the input variable set at the beginning of the simulation experiment. The model also allows for simulating a better "visibility" of the website on the Internet by generating a larger number of ConsumerAgents of a particular colour. The larger a number of ConsumerAgents of a particular colour, the higher likelihood of finding a website selling a particular type of product.

Apart from finding SellerAgents and BannerAgents, ConsumerAgents can conduct interactions among themselves in a given radius while surfing through a virtual market. As mentioned above, it is in this manner that consumers' tendency to imitate (follow) the behaviours of other consumers and their recommendations (eWOM effect) is modelled. ConsumerAgents' interactions can be classed into two types: direct communication of ConsumerAgents and ConsumerAgents' recommendations on websites. ConsumerAgents' recommendations (positive or negative) as regards some SellerAgents and/or brands are conveyed at the end of the purchasing process.

The basic model presented in Figure 3 (blue boxes) can be expanded for the purpose of observing a business strategy related to promotional price reduction of product prices (green boxes in Figure 3). Promotional prices are among the most important attributes affecting a consumer's decision to purchase online. Promotional campaigns increase sales significantly and, as a rule, result in an increased profit of the company. The business strategy of reducing prices in turn results in an increase in online sales by attracting a larger body of consumers. Price reduction is a key attribute affecting the consumer decision to purchase and it significantly increases the volume of online sales (Liu et al, 2013).

\subsection{Components of utility function}

The consumer's utility function is created on the basis of the information the ConsumerAgent collects on a product and in interactions with other consumers. At the beginning of a simulation it is possible to define the lowest utility function value below which the ConsumerAgent never makes a pro-purchase decision. Suppose that $\mathrm{N}$ brands were present at a virtual market. If we view incentives as independent variables, and character traits as coefficients of these independent variables, we can define the function in the following manner:

where:

$$
U_{i}=P_{i}+A_{i}
$$

$U_{i}$ - function of ConsumerAgent as regards product $i(i=1$ to $N)$.

$P_{i}$ - ConsumerAgent rating of the $i$-th product price and quality.

$A_{i}$ - effect of the $i$-th product marketing campaign on ConsumerAgent.

In product rating consumers usually trafe off between what they get by purchasing the product and how much money they give in return. The model observes price as one product attribute and product quality as the other, integrating all the aspects of product quality. 


$$
P_{i}=C_{i}+E Q_{i}
$$

where:

$P_{i}$ - ConsumerAgent's rating of the $i$-th product price and quality.

$C_{i}$ - ConsumerAgent's sensitivity to the $i$-th product (brand) price.

$E Q_{i}$ - ConsumerAgent's sensitivity to the $i$-th product (brand) quality.

The value of coefficient ${ }^{C_{i}}$ shows the effect of product price on the ConsumerAgent's attitude towards purchasing the given product. As a rule, higher prices tend to have a negative effect on consumers' motivation to buy a certain product. The distributed model of sensitivity to price (Kim et.al 1995) suggests that a lower price of a product generates a lower sensitivity to product price in a ConsumerAgent. Sensitivity to price can be expressed as follows (Zhang T, Zhang D, 2007):

$$
C_{i}=-\alpha P_{r i}-P_{e i}+k
$$

where:

$\square$ - consumer's rating $(\square>1)$ versus the real price of the observed product;

$P_{r i}$ - price of the $i$-th product;

$k$ - constant for ConsumerAgent which depends on socio-economic attributes (better-off consumers are less price-sensitive);

$P_{e i}$ - expected price of the $i$-th product; this parameter is difficult to define so it will be replaced by a mean value of all the products in the observed category $P_{\text {ave }}$

$$
P_{e i}=P_{a v e}=\frac{1}{N} \sum_{i}^{N} P_{e i}
$$

So that after the replacement we obtain:

$$
C_{i}=-\alpha P_{r i}-P_{\text {ave }}+k
$$

The next key attribute the consumer-agent rates is the product quality. The coefficient $Q_{i j}$ denotes the coefficient of $i$-th consumer-agent sensitivity to $j$-th product price. Sensitivity to quality is a multidimensional variable since the brand, that is, the product may have a number of quality aspects. Assuming that product $i$ has $m$ quality aspects, and on the basis of the model shown in (Jager, 2008), ConsumerAgent's rating of the $i$ th brand can be calculated as follows:

$$
E Q_{i}=\sum_{j=1}^{m} \beta_{i j} Q_{i j}
$$

where:

$Q_{i j}$ - j-th quality aspect for brand $i$;

$\beta_{i j}$ - weight of the $i$-th quality aspect for brand $j$ (value ranging between 0 and 1 ).

The next element of utility function regards the consumer-agent sensitivity to eWOM effect as well as sensitivity to marketing campaigns. Analytically, it can be expressed as:

$$
A_{i}=\alpha_{i} W_{i}+\beta_{i} B_{i}
$$

where:

\footnotetext{
$A_{i}$ - effect of the $i$-th product marketing campaign on ConsumerAgent.

$\alpha_{i}$ - ConsumerAgent's sensitivity to eWOM effect for product $i$;

$W_{i}$ - effect of other ConsumerAgents on decision to purchase the $i$-th product.

$\beta_{i}$ - ConsumerAgent's sensitivity to brand $i$ marketing (value ranging between 0 and 1 );

$B_{i}$ - number of banners for brand $i$ ConsumerAgent sees during his Internet surf.
}

The effect of eWOM on ConsumerAgent can be calculated in the following way (Aggarwal et.al. 2012): 
b) $\mathrm{W}_{\mathrm{i}}=\frac{E_{p}^{2}-E_{p} E_{n}}{\left(E_{p}+E_{n}\right)^{2}}$

where:

$E_{p}$ - number of positive rates of interaction.

$E_{n}$ - number of negative rates of interaction.

ConsumerAgents rate their interaction with seller-agents following each purchase made. The percentage of negative comments is an input parameter into a simulation model and is a subject of calibration in the simulation experiment.

The model also observes the interaction between ConsumerAgents and BannerAgents that represent banners on the Internet. ConsumerAgent's sensitivity to marketing campaigns (banners) can be determined as follows:

$$
B_{i}=\frac{R_{i}}{R}
$$

where:

$R_{i}$ - number of BannerAgents of brand $i$ in the BannerAgent's surroundings.

$R$

- total number of BannerAgents in the ConsumerAgent's surroundings.

The simulation model uses the utility function as basis for the purchase decision making. All the incentives in the model are viewed as variables that can be changed with every other experiment. The process of evaluation of all impact parameters and their ranking for the purpose of purchase decision making is modelled by the utility function. In the simulation experiment it is possible to consider or exclude each of the four members of the utility function. In this way it is possible to test all influential factors separately or in any mutual interaction

\section{Simulation experiment}

The observed simulation model is implemented in the NetLogo software. It was subjected to a number of experiments and data are collected for an analysis of the behaviour of B2C online sales system. The basic indicators of B2C sales site business that were observed are market share and the number of visits on the website (surf share). At the beginning of simulation ConsumerAgents, ConsumerAgents and BannerAgents are generated, as described earlier in the paper. The simulation ensures that impact factors from the utility function that affect the consumers' behaviour are observed separately.

In the initial simulation experiment all types of products are assigned the same price in the amount of 100 monetary units, as well as the same quality level. Thus all the Internet sites have the same initial conditions for business. For every purchase the ConsumerAgents contact four websites (SellerAgents) in their surroundings. This number is an input parameter and can be changed depending of the scenario we wish to test. After an initial oscillation, the SellerAgents' market share stabilizes and both visits and sales are almost evenly distributed across SellerAgents. This is an obviously expected result given equal initial business conditions set in the model and, in a certain way, may be used in model verification.

In the next stage of the simulation experiment we observed the effect of eWOM on the output variables of the model. The graph in Figure 4-a shows that the sales of, in that time, best-sold products (yellow and green) increased most rapidly. The price of the products remains the same and so does the quality, however, consumers most often "comment" the best selling products, which further improves their sales. The intensity of the eWOM effect, depending on the selected scenario, can be adjusted through the "choiceneighbours-buyers" input parameter that determines the radius in which ConsumerAgents follow other ConsumerAgents who have already purchased the observed product. The broader the radius, the more powerful the eWOM effect on the utility function. In case of eWOM effect on the increase in surf share, it can be concluded that this effect is of minimum importance, as shown in the graph in Figure 4-b. 


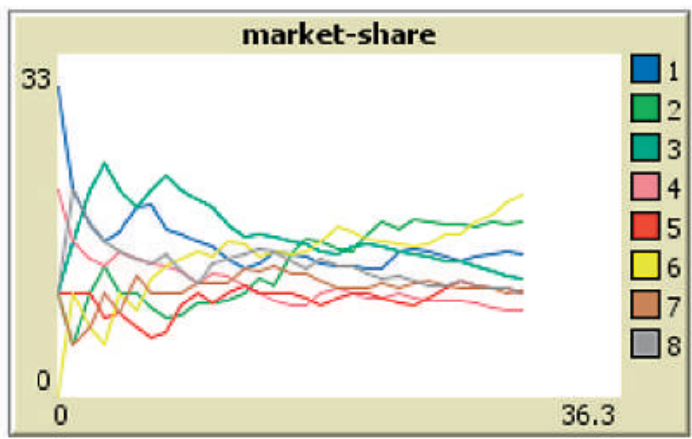

Figure 4-a. Graph: eWOM effect on market share

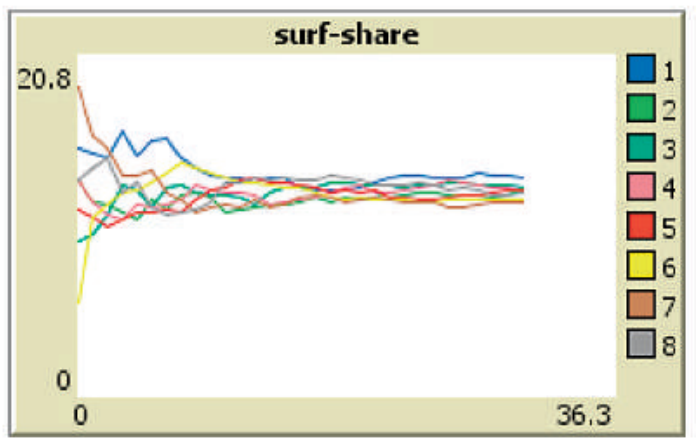

Figure 4-b. Graph: eWOM effect on surf share

In the following stage of the simulation experiment we include the effects of product marketing through BannerAgent generation. In this iteration, 20 banners were generated for pink and red products, and the clickthrough-rate (CTR) was set at $10 \%$. The $10 \%$ coefficient for CTR is unrealistically high (in practice, this coefficient normally amounts to $4 \%$ ), however, we did this to illustrate the sensitivity of the model to an abrupt rise of this coefficient (Figures 5-a and 5-b).

Now we notice that the surf share on websites that sell the "pink" and the "red" products has increased significantly in comparison with the competition (Figure 5-b). However, even though the sales of the "red" product increased slightly, this type of advertizing had no effect on the increase in the "pink" product sales. This can be explained by the fact that the "pink" product has so far had the smallest market share (Figure 5-a), hence the eWOM effect on it was modest, and the applied level of marketing has not been powerful enough to alter the situation to a more significant extent. In this way it is possible to test different business policies related to the effects of internet marketing by way of banners.

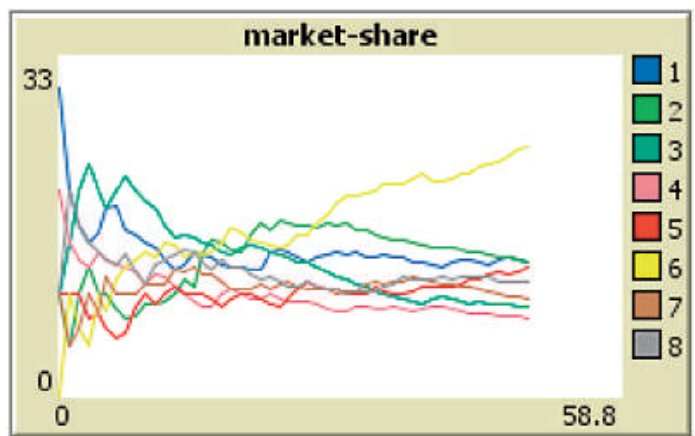

Figure 5-a. Graph: BannerAgent effect on market share

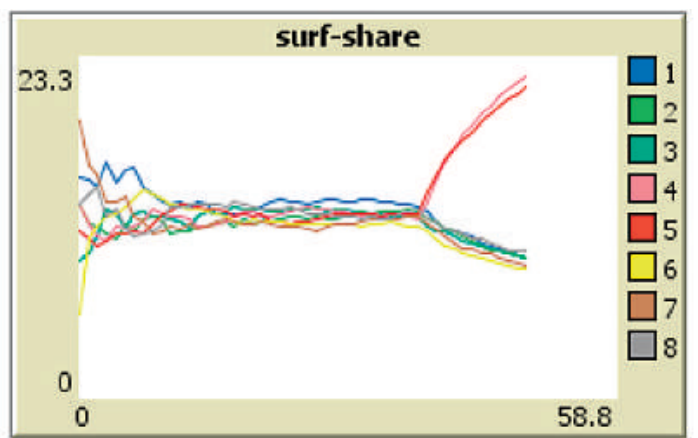

Figure 5-b. Graph: BannerAgent effect on surf share

Upon discontinuing the simulation, the experiment continues to test the effect of increasing the "visibility" of the website through increasing the ratings on the browsers. We will increase the "visibility" of SellerAgents by assigning weights for their search. At the same time we define the number of websites randomly searched with these weights. We will now assume that a majority of consumers browsing the Internet will check a certain number of top-ranked sites from the list of offered sites (in this experiment we will choose three), while in further browsing they choose the remaining sites randomly. The number of websites browsed on the basis of search weights and of those browsed randomly are input variables into the simulation model.

Figures 6-a and 6-b show that in this case, again, the number of visits to sites increases, as well as their sales after a certain time. We can draw a conclusion that investment into a better visibility of a site on the Internet increases the number of visits and sales to a larger extent in comparison with marketing via banners, which should be taken into consideration when planning the site promotion costs. 


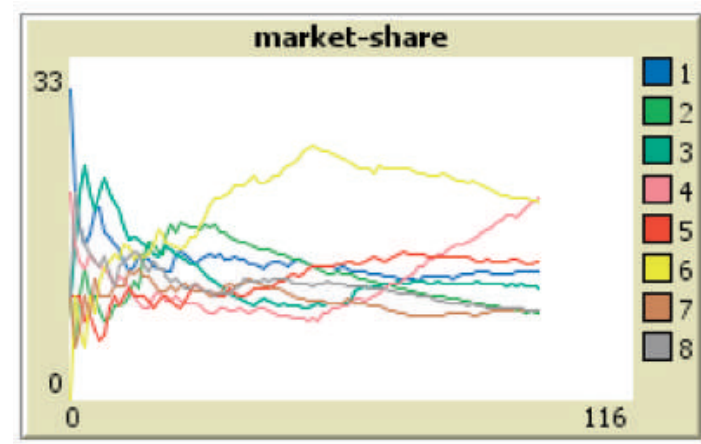

Figure 6-a. Graph: SellerAgent search weights effect on market-share

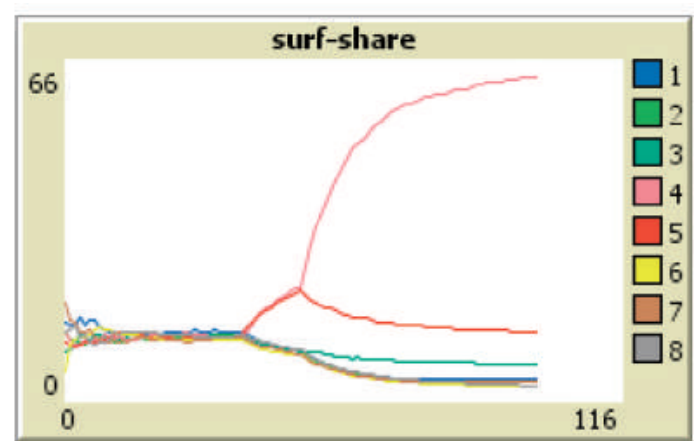

Figure 6-b. Graph: SellerAgent search weights effects on surf-share

In the final stage of the observed simulation experiment we test the effect of the product price and quality change on the online sales. The prices of the best-selling "pink" and the second best, "yellow" products increased by $5 \%$ and $3 \%$, respectively, whereas the price of the worst-selling, "grey" brand decreased by $5 \%$. Simultaneously, the quality of the "blue" product improved by $5 \%$, and that of the "red" product improved by $3 \%$. Effects of these changes can be seen in the graphs in Figures 16-a and 16-b.

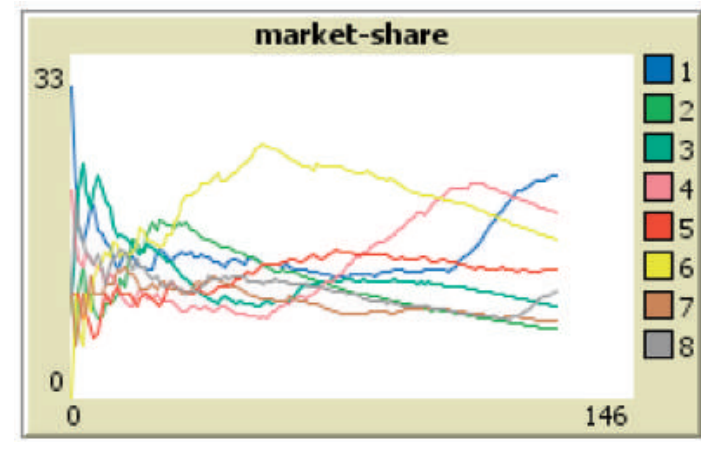

Figure 7-a. Graph: Effect of price and quality change on market share

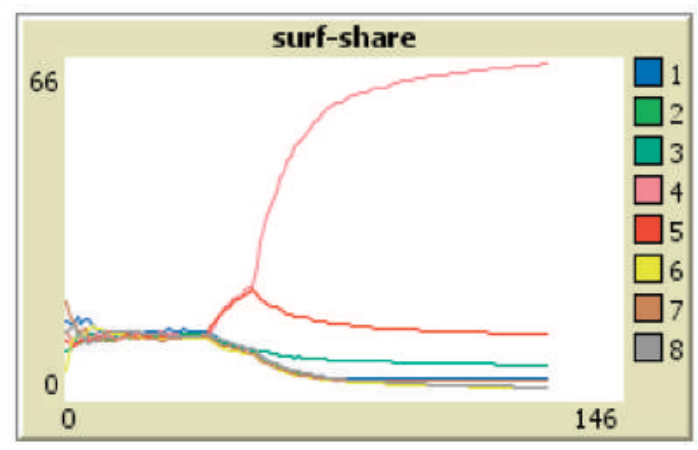

Figure 7-b. Graph: Effect of price and quality change effect on surf-share

We can see from the graphs in Figures 7-a and 7-b that these relatively small changes in prices and quality do not have an immediate effect on the sales of the product, however, sales still improve over time. The increase in sales of the "red" product on the basis of improved quality is somewhat slower, though. This may be a result of relatively slack marketing activities of the observed Internet seller, but also of the time required that the improvement of the product quality on the market should have a beneficial effect on sales.

The analysis of the obtained results proves that the model is capable of simulating various business policies and market effects on online B2C sales. We began the first simulation experiment with equal conditions of sale for all online shops, whereby we achieved a market balance with similar numbers of visits and sales for all SellerAgents. We continued the experiment to test the business policies of on-line promotion, product price variations, product quality variations and variations in the quality of the Internet site 


\section{Conslusion}

The research proves that the methodology of agent-based simulation and modelling can be successfully implemented in modelling and simulation of processes on online markets. It also shows that the results obtained can be successfully used to analyse the behaviour of such markets and monitor the effects of different business strategies of online sellers on generated sales, site visits and other success indicators in doing business in the e-commerce domain.

For the needs of this research a simulation model was developed in the NetLogo software that enables us to monitor the key interactions of the core players on the online market. The generated agents who present the dynamic entities of the model are assigned attributes based on empirical and theoretical data retrieved from the $\mathrm{B} 2 \mathrm{C}$ online market. Thus the online market managers are provided with the tool to investigate into the impacts and effects of implementing their own business strategies to the market flows.

The rules of behaviour and interactions included into the model stress the complexity of the decision-making process in product evaluation and purchase in the B2C e-commerce segment. The observed simulation model includes a broad range of impact variables whose aim is to model all the relevant aspects of consumer behaviour and explain their method of decision making when purchasing on-line.

We can conclude that the designed e-commerce simulation model is a tool that ensures a better insight into the issue of consumer behaviour on the Internet, and the companies engaged in e-commerce in the $\mathrm{B} 2 \mathrm{C}$ segment now have a tool that can help them better understand their consumers, improve market segmentation, improve the business profitability and test their business strategies. As shown in the above discussions, consumer decision making on the Internet is the subject of continual study, therefore, new insights and approaches are certainly out there, waiting to be explored, which opens a broad area for further study.

\section{LITERATURE}

[1] Aggarwal R, Gopal R, Gupta A, Singh H, Putting Money Where the Mouths Are: The Relation Between Venture Financing and Electronic Word-of-Mouth, Journal Information Systems Research Archive 2012, 23:976-992

[2] Belch E, Belch A, Advertising and Promotion: an integrated marketing communications perspective, Irwin McGraw-Hill (4 ed.) 1998.

[3] Changa M,Cheungb W, Laib V, Literature derived reference models for the adoption of online shopping, Information \& Management 2005, 42: 543-559.

[4] Engel J, Blackwell R, Miniard P, Consumer Behavior, The Dryden Press (8th ed.) 1994.

[5] Gilbert N, Troitzsch G, Simulation for the social scientist, Open University Press McGraw-Hill Education 2005.

[6] Godes D, Mayzlin D, Using Online Conversations to Study Word of Mouth Communication, Journal Marketing Science archive 2004, 23:545-560

[7] Hyung A, Evaluating customer aid functions of online stores with agent-based models of customer behavior and evolution strategy, Information Sciences 2010, 180:1555-1570.

[8] Jager W, Simulating consumer behaviour: a perspective, paper prepared for the Netherlands Environmental Assessment Agency project "Environmental policy and modelling in evolutionary economics" 2008,

[9] Kim B, Blattberg R, Rossi P, Modeling the distribution of price sensitivity and implications for optimal retail pricing, Journal of Business \& Economic Statistics 1995, 13:291-303

[10] Klever A, Behavioural Targeting: An Online Analysis for Efficient Media Planning?, Diplomica Verlag 2009.

[11] Liu X, Tang Z, Yu J, Lu N, An Agent Based Model for Simulation of Price War in B2C Online Retailers, Advances in Information Sciences and Service Sciences 2013, 5: 1193-1202

[12] Miller J, Page S, Complex Adaptive Systems: An Introduction to Computational Models of Social Life, Princeton University Press 2007.

[13] Moe W, Buying, searching, or browsing: Differentiating between online shoppers using in-store navigational clickstream, Journal of Consumer Psychology 2003, 13:29-39. 
[14] Moe W, Fader S, Fast-Track: Article Using Advance Purchase Orders to Forecast New Product Sales, Marketing science 2002, 21:347-364.

[15] Prokopenko M, Boschetti F, Ryan A, An information-theoretic primer on complexity, self-organisation and emergence, Complexity 2009, 15:11-28.

[16] Radenkovic B, Stanojevic M, Markovic A, Racunarska Simulacija, Faculty Of Organisational Sciences, Belgrade 2001.

[17] Schiffman L, Kanuk L, et al., Consumer Behavior, New Jersey: Prentice Hall (10th ed) 2009.

[18] Solomon M, Bamossy G, Askegaard S, Consumer Behaviour: A European Perspective, Prentice Hall 2009.

[19] Zhang T, Zhang D, Agent-based simulation of consumer purchase decision-making and the decoy effect, Journal of Business Research 2007, 60:912-922.

Receieved: October 2015. Accepted: December 2015.

\section{Sava Čavoški \\ MDS informaticki inzenjering scavoski@mds.rs}

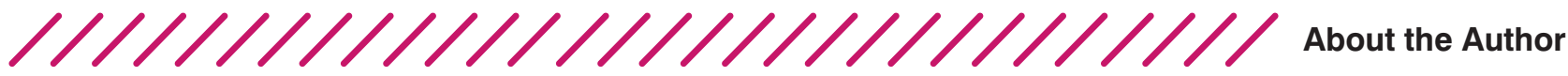

Sava Cavoski has an extensive experience as a software architect. The following projects are worth mentioning: the Development of KOSTMOD 4.0 software project (it included the cooperation between Forskningsinstitutt (FFI) within the Ministry of Defence of the Kingdom of Norway, the Ministry of Defence of Serbia and the Faculty of Organisational Sciences, University of Belgrade; the Billing software for Cisco

IP Telephony and the Laboratory Information System (LIS) for the biggest laboratory chain in the Republic of Serbia. He published extensively in the field

of simulation and simulation modelling in domestic and international journals. His main areas of interest are the simulation models in finance, agent-based simulation models and Cloud Computing.

\section{Aleksandar Markovic \\ University of Belgrade, Faculty of Organizational Sciences,Serbia aleksandar.markovic@fon.bg.ac.rs}

Aleksandar Markovic is a Full Professor at the Faculty of Organizational Sciences, University of

Belgrade, Serbia, where he acquired his MSc and PhD degrees in the field of Computer

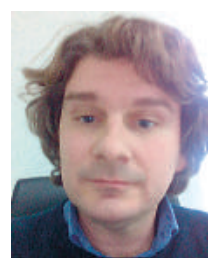

Simulation. He is currently the Vice-Dean for finance and organisation. Areas of his

research include: Computer Simulation, Simulation for Business Decision Making,

Business Dyinamics and e-Business Management. Since 2009 he has been the editorin-chief of the International Journal "Management". 